\title{
Máscaras heterossexuais, desejos homossexuais*
}

A cena mais banal dos nossos cotidianos é entrar em qualquer espaço público e nos depararmos com uma legião de pessoas acopladas aos seus smartphones. Essas próteses existenciais parecem grudadas aos nossos corpos. Olhos vidrados, dedos ágeis, corpos eretos. Talvez ali, diante de nós, um encontro sexual, via algum aplicativo, esteja sendo marcado. Depois de um checklist dos atributos do futuro parceiro de noite, o encontro é marcado. Dois homens, distantes não sabemos o quanto, protegidos por senhas, criptografias, fakes, podem, finalmente, viverem seus desejos. O que buscam? São gays ou heterossexuais? $\mathrm{O}$ anonimato das telinhas os torna mais livres? $\mathrm{O}$ que é liberdade em contextos onde decidimos pouco sobre as normas sociais?

Ao longo dos sete capítulos, Richard Miskolci analisará os usos das mídias digitais por homens que procuram parceiros sexuais e amorosos do mesmo sexo. Um dos objetivos do livro Desejos Digitais: uma análise sociológica por parceiros on-line (2017) é compreender como homens têm negociado a visibilidade/invisibilidade do desejo homossexual mediante o uso de meios tecnológicos. Antecipo (e peço desculpas por esse meu lado spoiler) que somos jogados em um mundo de segredos, controles, autocontroles, medos e frustações. Os aplicativos parecem liberar, em intensidades distintas, o que esses homens consideram ser seus "black mirrors". A parte do eu que não ousa

* Recebida em 26 de novembro de 2017, aceita em 29 de novembro de 2017. Resenha do livro MiskolCI, Richard. Desejos Digitais: uma análise sociológica por parceiros on-line. São Paulo, Autêntica, 2017.

** Professora do Departamento de Sociologia da UnB, Brasília-Df, Brasil. berenice.bento1@gmail.com 
sair. As frestas agora têm nomes: Grindr, Hornet, Scruff, Tinder e Happn.

O livro é resultado de uma pesquisa realizada entre os anos 2007 e 2016 e teve como campo as cidades de São Paulo e San Francisco (Estados Unidos). O pesquisador, ao longo desses anos, acionou múltiplos métodos, sem nenhum tipo de ortodoxia: "observação acompanhante", entrevistas abertas, observação interativa nos aplicativos, pesquisa histórica, etnografia e lurking (observação on-line de plataforma). Foram entrevistados centenas de homens que conheceu via plataformas on-line como batepapos, sites $e$ aplicativos de busca de parceiros sexuais $e$ amorosos.

As duas últimas décadas são o recorte temporal da pesquisa, que tem como foco principal a geração de homens paulistanos que nasceram a partir da década de 1970. Entre tantos achados, a pesquisa descobriu que, embora esses homens tenham nascido em uma época de grandes transformações sociais - a Revolução Sexual -, não obtiveram os dividendos dessas mudanças, principalmente devido à ditadura militar $e$ ao pânico moral advindo com a aids. A internet, já na década de 1990, foi um meio para experienciar os desejos por outros homens, sem assumir uma identidade gay e sem romper com as expectativas que sustentam a alma da heteronorma: a constituição de familias heterossexuais. Essas conclusões referem-se à pesquisa realizada em São Paulo. O uso da tecnologia para evitar controle ou retaliação moral permite que homens - mesmo com companheiras mulheres - mantenham relações esporádicas ou contínuas com outros homens. Em sua maioria, os colaboradores da pesquisa se compreendiam como heterossexuais e não lutavam pelo reconhecimento de uma identidade bissexual ou homossexual.

Tanto em São Paulo quanto em San Francisco, há uma permanente negociação com a visibilidade do desejo homossexual. No contexto de San Francisco, o sociólogo analisa como os homens gays vivem sob o império do medo de uma possível contaminação do hiv. Um dos efeitos desse medo foi a 
capturação expressa na adesão a modelos tradicionais, a exemplo do casamento entre pessoas do mesmo sexo.

O livro está inserido em um campo de pesquisas das humanidades que remonta aos 1980 e que tem desconstruído os discursos hegemônicos que afirmam que nossos desejos são oriundos de alguma parte dos corpos. Ao fazer tal movimento, essas pesquisas acabam por liberar as identidades sexuais e de gênero de uma suposta fixidez. Ao longo dessas décadas, temos produzido um tipo de teoria social que tem contribuído densamente para o pensamento social brasileiro. No contexto histórico brasileiro, podemos afirmar que sexualidade e gênero são categorias analíticas (e políticas) com o mesmo status que classe social e raça. Não é mais possível pensar as relações sociais no Brasil sem fazer referência a esse campo do pensamento social brasileiro: os estudos dos gêneros e sexualidades dissidentes.

Nenhum outro pensador nas Ciências Sociais brasileira tem se dedicado com tanto afinco, rigor e teimosa intelectual em pensar o "desejo" como uma categoria analítica sociológica quanto Richard Miskolci. No seu livro $O$ Desejo da Nação: masculinidade e branquitude no Brasil de fins do XIX (2012), entre outras discussões que realiza, defende que a implantação do serviço militar obrigatório no Brasil pode ser lida como uma prática de controle da sexualidade na qual a suspeita da homossexualidade tornou-se um critério para a seleção dos recrutas.

\section{Imaginação e método}

$\mathrm{Na}$ busca por compreender quem são e o que desejam os homens usuários de aplicativos voltados para encontros amorosos $e$ sexuais com outros homens, podemos acompanhar $\mathrm{O}$ movimento do pensamento do autor. Ele parte de narrativas individuais para, no momento seguinte, relacioná-las a contextos sociais e históricos e, num terceiro movimento, retorna para as narrativas biográficas. Assim, metodologicamente, ele insere as experiências em quadros históricos, políticos, econômicos e sociais 
mais amplos. Não desconsidera, em nenhum momento, que os sentidos históricos encontram sua concretude nos indivíduos sem, no entanto, ler as narrativas dos seus colaboradores de pesquisa como autoevidentes ou transparentes (Scott, 1998). Desconfia, portanto, que ali, no momento da narrativa do "eu", há uma polifonia de vozes.

Talvez Miskolci tenha adotado um dos pressupostos teóricos mais importantes para pesquisadores/as que acionam as vidas de outras pessoas, escutam relatos biográficos, uma vez que o "eu" está, desde sempre, "implicado numa temporalidade social que excede suas próprias capacidades de narração" (Butler, 2015:18). E aqui o desafio do/a pesquisador/a é articular esse particular com dimensões mais abstratas. Nesse jogo, pode-se notar as crises, as fissuras que Adorno (apud Butler, 2015) discutirá em termos de violência ética, ou seja, quando valores universais não abrem espaço para que novas formas de vida surjam. Os dispositivos tecnológicos, conforme pesquisado por Miskolci, mais do que trazer para o mundo público o enfrentamento com essas normas, parecem ter se tornado um mecanismo a mais de proteção das normas e, ao mesmo tempo, um caminho possível para se viver desejos sem correr risco, sem submeter-se à violência, sem rompimento de vínculos.

Tais procedimentos metodológicos poderiam, à primeira vista, sugerir uma falta de cuidado com a experiência, afinal, os sujeitos estão ali, diante de Richard Miskolci, em algum café em São Paulo ou em San Francisco, homens que se relevam, "narram-se", contam suas histórias. Não bastaria transcrevê-las?

O mundo empírico, o real, não está ali parado, esperando para ser decifrado. Precisamos sair do "dado", da fala, e inseri-la em contextos históricos mais amplos e, ao fazer isso, mais do que rigor e erudição (qualidades que abundam nessa e em outras obras de Miskolci), a imaginação do/a pesquisador/a é fundamental. Então, seria o livro uma pesquisa ou uma obra ensaística? Onde localizá-la? Em qual gênero de conhecimento podemos defini-la? 
Para Baruch Spinoza (2008) há três gêneros do conhecimento - ou estéticas da existência. No primeiro, o sujeito é escravo, porque tudo que deseja saber da vida é motivado pelo desejo exterior ao eu. Aqui não se produz nada, apenas se obedece aos estímulos externos. No segundo gênero, o conhecimento advém da relação da descoberta do funcionamento da natureza. Busca-se conhecer aquilo que está fora. Ou seja, não há criação, apenas revelação. Passa-se a conhecer aquilo que já existe. Seria o gênero próprio das ciências, pois, se busca a verdade mediante a utilização de métodos sistemáticos. $\mathrm{E}$, finalmente, o terceiro gênero, no qual o sujeito cria algo novo, outras formas de existir. Aqui surge a questão da liberdade, reino das artes.

Acredito que a Sociologia de Richard Miskolci se localiza em outro gênero de conhecimento. Não é pura criação, porque está a todo o momento colando e recortando falas de outros (sejam teóricos/as e/ou colaboradores da pesquisa), em um trabalho de bricolagem intelectual. Tampouco é ciência, nos termos de descobertas irrefutáveis, portadora de um selo de cientificidade advinda da utilização de métodos repetíveis (a prova científica). Ora, o próprio pesquisador, em atos éticos ousados, coloca seu próprio corpo como elemento que afeta sua pesquisa, o que o distancia de qualquer possibilidade de uma ciência positivista. E, para lembrar mais uma vez Spinoza (2008) não se trata, aqui, de nos perguntamos o que pode um corpo. Richard insinua outra questão: o que pode um corpo de um/uma pesquisador/a? A sua branquitude foi uma variável importante em suas interações com o campo. Se o pesquisador fosse negro, quais seriam os resultados da pesquisa?

Entre a criação (arte) e a descoberta (ciência) localiza-se o pensamento de Richard Miskolci. Como entender o medo dos homens em serem descobertos em seus desejos por outros homens? Para propor interpretações sobre os jogos de visibilidade/invisibilidades, economias do desejo, economias eróticas, o sociológico segue os rastros das vozes e dos corpos dos seus colaboradores. 
Muitas vezes digo para os/as estudantes que ser sociólogo/a é estar em constante flerte com a esquizofrenia. Somos seres desconfiados. Se alguém diz: "isso é uma parede", podemos retrucar: "Não, isso é trabalho humano, pretérito materializado no valor de uso "parede". Se alguém diz: "Isso é um smartphone", Richard nos dirá que aquela tecnologia alterou padrões de flerte $e$ que passou a funcionar como tipo de prótese existencial que permite novos tipos de negociação dos desejos. Ali, com apenas um deslizar de dedo, há um "cardápio" inteiro de ofertas.

Em vários momentos, a leitura de Desejos Digitais me surpreendeu pela criatividade do autor. Não é uma obra que "usa" as teorias gringas como ferramenta; ao mesmo tempo, não há nenhum tipo de xenofobia teórica. Richard lê Foucault, inspirase no conceito de biopoder (1999) e afirma: não basta "aplicarmos" a teoria. Foucault não teorizou sobre uma esfera central na constituição de qualquer debate sobre desejo $e$ população: o mercado. O mesmo movimento acontece quando irá discutir com Sedgwick (2007) acerca da "epistemologia do armário". Richard é um legítimo herdeiro da tribo dos canibais intelectuais. Usa os conceitos de outros como inspiração para propor novas imagens e interpretações. Não estamos diante de um teórico que "aplica" as teorias usando-as como ferramenta. Miskolci as transforma em poesia que tem como finalidade lhe inspirar em sua fértil e erudita sociologia. A imaginação sociológica de Miskolci é o próprio tutano da obra.

Em um diálogo entre dois personagens de A Gaivota, de Anton Tchekhov (2010), acompanhamos o processo criativo de um autor. Nina diz para Trigórin, escritor famoso, que a vida dele deveria ser deslumbrante. Ele, para desconstruir essa imagem, nos leva aos seus segredos de produção e nos revela o sofrimento (uma obsessão) que se esconde no ato de escrever: "(...) Vejo uma nuvem parecida com um piano. Penso: em algum trecho de um conto, terei que citar que pairava no céu uma nuvem parecida com um piano (...) E é sempre assim, sempre, nunca dou sossego a mim mesmo (...)" (Tchekhov, 2010:52-53). 
Eu imagino Richard sentado, horas e horas acompanhando as páginas de seus colaboradores de pesquisa, tomando nota, lendo, fazendo pontes, quebrando outras. Posso imaginá-lo desassossegado, como nosso escritor Trigórin. E, em algum momento, um raio, uma solução. Richard nos oferece uma interpretação para a constante busca de parceiros em aplicativos: é a própria busca, a caça ritualizada, performatizada em espaços virtuais, que motiva o flerte continuado. É a caça que atualiza um dos principais atributos definidores das masculinidades hegemônicas: a virilidade.

\section{Jogos: visibilidade/invisibilidade}

Conforme afirmei, a pesquisa de Richard compõe o pensamento social brasileiro das sexualidades e gêneros dissidentes. $\mathrm{O}$ que as pesquisas nesse campo têm reiteradamente revelado como um dos eixos estruturais e estruturantes da sociedade brasileira é a aversão ao feminino enquanto performatizado em corpos construídos como masculinos.

As pesquisas sobre a honra familiar apontaram que são as mulheres as responsáveis pela proteção da boa reputação dos lares. Daí o controle permanente das sexualidades femininas e, em muitos contextos no Brasil, a virgindade feminina ainda é uma moeda simbólica fundamental.

As pesquisas das sexualidades dissidentes estão nos apontando para um tipo de variação da honra que continua sendo relacional e assimétrica: não mais exclusivamente nos corpos das meninas, mas um novo tipo de controle das performances dos meninos. Ser um homem e performatizar o feminino significa cobrir de vergonha e desgraça a família. É interessante porque aqui ainda é o feminino que funciona como elemento estruturante da honra da família. Os crimes de honra que povoam a história do Brasil (pais e maridos que matavam suas filhas/esposas para "limparem" a honra da família com sangue) são ressignificados no contexto das homossexualidades. 
São homens que podem, potencialmente, manchar a honra da família.

Então, por mais dolorosa que seja, ainda que cause sofrimento psíquico, antes performatizar o heterossexual para poder viver, em segredo, os desejos homossexuais, que sucumbir à morte social. O êxito de uma família (uma família honrada) dependerá agora não exclusivamente do comportamento da mulher, mas do comportamento do filho.

A pesquisa de Richard teve como foco as narrativas de sujeitos singulares, mas vale nos perguntarmos se a aversão ao feminino e o império da discrição funcionariam em casais homossexuais. A pesquisa de Cristian Paiva (2007) nos confrontará com um léxico próximo ao encontrado nas narrativas dos colaboradores de Miskolci. Paiva pesquisou casais gays $e$ afirmará que:

A exploração desse espaço "fraturado" entre o "dizer" e o "dar a ver" possibilita a afirmação do relacionamento no interior de laços familiares, de amizade, profissionais, numa complexa tensão entre reconhecimento e silêncio. (...) Esse "silêncio" mantido por arte dos familiares, dos amigos, dos colegas do trabalho etc., sobre o relacionamento pari passu com a intensificação dos contatos com os casais (isto é, um silêncio anuente), nos obriga a pensar uma outra "epistemologia do armário" (Sedwick, 1990). Quais são as regras desse manter-se escondido, isto é, ao abrigo de uma declaração pública, sobre os próprios amores e desejos, que, no entanto, se imiscui à vista de todos, sem que ele seja falado? Portanto, uma visibilidade dos interstícios e não uma visibilidade ostensiva (Paiva, 2007:29).

Paiva considera que a discrição "não se trata de uma "volta ao armário', mas de uma economia (no sentido econômico de fazer uma reserva) da intimidade frente a uma exposição sentida como excessiva" (Paiva, 2007:32). Aqui também há um léxico compartilhado com os colaboradores de Richard: discrição, distância, invisibilidade. Os casais se afastam de qualquer 
movimento político que levante a bandeira do arco-íris. $\mathrm{O}$ autor aponta que essa seria uma forma de micropolítica, mas as falas dos colaboradores nos levam a pensar que o armário apenas se ampliou para incluir amigos, familiares e conhecidos.

$\mathrm{O}$ que é ser discreto? O que deve ser escondido? Será que esses casais da pesquisa de Cristian Paiva se beijam, mostram-se como corpos desejantes diante de seus familiares e rede de sociabilidade?

Leandro Colling (2013) pesquisou quais as estratégicas utilizadas pela Rede Globo para incorporar personagens gays em suas novelas. $\mathrm{O}$ corpus analítico foi composto por 10 novelas dessa rede. Para Colling, há um fio condutor entre eles: a discrição na demonstração de corpos desejantes. Onde estão as cenas de casais gays e lésbicas na cama se beijando? Segundo Colling (2013:106-107),

(...) os gays e lésbicas parecem assexuados, os casais não se beijam, praticamente sequer trocam carícias, ou seja, sua vida sexual é nula. Isso ocorre certamente para não chocar ou afastar telespectadores e também atende aos interesses de um pensamento marcado pela heteronormatividade.

Cito apenas essas duas pesquisas para corroborar que estou chamando atenção para a centralidade do feminino na estruturação das relações sociais $e$ na ressignificação dos sentidos de "honra" em contextos de sexualidades e gêneros dissidentes. A centralidade do feminino leva-me a questionar o porquê o movimento gay masculino mainstream não assume como agenda estratégica de luta uma perspectiva feminista. Seria também o medo da contaminação? Façamos movimento social, mas sejamos discretos? O núcleo central da homofobia é a misoginia. Esse talvez seja o ponto de unidade entre as pesquisas que estruturam o pensamento social das sexualidades dissidentes. 
Tão logo o livro de Richard foi publicado, o devorei e, imediatamente, o incluí nas leituras obrigatórias do meu curso de Introdução à Sociologia. Em uma sala de aula com "bichas da periferia" (como algumas/alguns estudantes se identificam), com heterossexuais, lésbicas, negros, brancos, o texto de Richard foi combustível para relacionar vida e teoria, abstração e empiria. "Finalmente, um texto que dá sentido ao que vivemos", afirmou um estudante. "Foi um dos textos mais importantes que já li em toda minha vida", disse outro. E, por fim, um estudante heterossexual, com ares de desabafo: "mas eles lutam para serem reconhecidos como heterossexuais?".

Pode-se propor uma estrutura nos regimes de visibilidade. $\mathrm{O}$ referente, o universal, no qual as identidades abjetas se apropriam para tornarem a vida vivível, num primeiro momento, se dá pela utilização de máscaras para serem aceitos pelos considerados "senhores/as". Apenas nesse primeiro momento concordaria com a dialética colonial de senhor e escravo nos termos proposto por Hegel (1992). Talvez a noção de "passibilidade heterossexual" seja uma aproximação com a de alienação do sujeito negro proposto por Franz Fanon (2008) e da mascarada de Joan Rivière (2004). Ou seja, eu preciso me inserir na lógica do outro (o senhor) para ser reconhecida como merecedora de viver. Mas esse tipo de reconhecimento acontece tendo como fundamento a violência psíquica. Preciso articular um conjunto de estratégias que apague a minha negritude, ou o meu gênero feminino, ou a minha homossexualidade. Reconhecimento, nesses termos, produz apagamento e silenciamentos de outras formas de existência não aceitas hegemonicamente. O subalterno sexual, de gênero, de raça, para existir, precisaria se apropriar e incorporar a linguagem do senhor. Esse seria o caso dos homens gays de San Francisco entrevistados por Miskolci. São homens gays, com máscaras heterossexuais. Não estou aqui sugerindo uma recitação do binário. As máscaras (numa clara referência ao trabalho de Fanon $e$ de Rivière) aqui estão no culto ao corpo, na performance máscula e na aversão ao feminino. No caso dos homens paulistanos, não há nenhuma demanda de reconhecimento de 
identidade gay. Portanto, se há desejo homossexual, a existência social é heterossexual.

No entanto, valeria pensar, a partir das provocações de Miskolci: será que aquilo que Hegel apontou como fenomenologia da constituição do "eu" não seria, na perspectiva do/a subalterno/a, desde sempre, estratégias de sobrevivência? Tendo a defender que não se trata de uma estrutura que explicaria que nos tornamos sujeitos a partir do desejo de reconhecimento do outro, mas de estratégicas conscientes de luta pela sobrevivência. $\mathrm{O}$ sujeito subalternizado não está em uma relação de ausência de consciência, daí ser precária a noção de "consciência de si" $e$ "consciência para si" (Hegel, 1992). Ao contrário, a todo o momento é preciso, nas múltiplas interações cotidianas, provar que sou um gay heterossexual exemplar. Se contorcermos Hegel, veremos em sua dialética, antes de tudo, uma teoria da agência na qual eu preciso do senhor até determinado momento. Qual o momento? Quando transformo o insulto em posição identitária positivada e a vergonha transforma-se em combustível de luta. Não desejo mais o desejo do senhor. Deixo de ser escrava porque já não sou mais controlada por uma força exterior que me constitui e "me coloco" no mundo com linguagens com outros modos de existência. É nesse momento que a fenomenologia colonial hegeliana desaba.

A dialética do "senhor e escravo" nos ajuda a pensar, ainda que anemicamente, essa busca de reconhecimento via assimilação que se efetiva nos marcos da heteronormatividade. Seria possível outras formas para se demandar reconhecimento? Já caminhando para o final, Miskolci nos apresenta algo novo que está acontecendo nos aplicativos. Jovens gays que se negam a contribuir com a reprodução do jogo das homossexualidades hegemônicas e que passam a demandar o direito à voz fina $e$ às performances femininas. Aqui, já não estamos nos marcos do subalterno de Spivak (2010). Esse, acredito, é momento em que as barragens são rompidas. Não se trata mais de concordar em ficar ali esperando, desejando o desejo do senhor (Hegel, 1992) de regular meu desejo para ser amada e respeitada pelo outro. A 
usina explode, as compotas são arrebentadas. Há algo novo acontecendo. Mas esse "algo novo" não é uma síntese, uma solução. A dialética hegeliana não alcança esses sujeitos transviad@s. A psicanálise lacaniana não demora em carimbá-los de psicóticos. O simbólico, a linguagem binária da diferença sexual, se perde diante da demanda de gays femininos, das bichas que embaralham as fronteiras de gênero $e$, ao fazê-lo, nos apresentam cartografias outras para os desejos.

Ao terminar o livro de Richard Miskolci com essas bichas maravilhosas que agora parecem fazer um movimento rizomático de ocupação virtual dos aplicativos, fui levada a concluir que algo novo está acontecendo ali. Quem sabe esse não seja o terceiro livro da trilogia de Richard Miskolci em sua sociologia do desejo?

\section{Referências bibliográficas}

ButLeR, J. Relatar a si mesmo: crítica da violência ética. São Paulo, Autêntica, 2015.

ColuING, Leandro. Mais visíveis e mais heteronormativos: a performatividade de gênero das personagens não-heterossexuais nas telenovelas da Rede Globo. In: COLLING, Leandro; THÜRLER, Djalma (org.). Estudos e políticas do CUS. Grupo de Pesquisa Cultura e Sexualidade. Salvador, EDUFBA, pág. 23-46, 2013.

FANON, F. Pele negra, máscaras brancas. Bahia, EDUFBA, 2008.

Foucault, M. Em defesa da sociedade. São Paulo, Martins Fontes, 1999.

Hegel, G. W. F. Fenomenologia do Espírito. Petrópolis, Vozes, 1992.

MISKOLCI, Richard. O Desejo da Nação: masculinidade e branquitude no Brasil de fins do XIX. São Paulo, Annablume, 2012.

. Desejos Digitais: uma análise sociológica por parceiros on-line. São Paulo, Autêntica, 2017.

PAIVA, Antônio Cristian Saraiva. Reserva e invisibilidade: a construção da homoconjugalidade numa perspectiva micropolítica. In: GROSSI, Miriam et al. (org.). Conjugalidades, parentalidades e identidades 
lésbicas, gays e travestis. Rio de Janeiro, Garamond, pág. 87-110, 2007.

RIVIÈRE, J. A feminilidade como mascarada. Phoenix - Revista da Delegação Paraná da Escola Brasileira de Psicanálise (4), 2004, pp.91-102.

ScotT, Joan. A visibilidade da experiência. Proj. História, no 16 , São Paulo, PUC-SP, fev. 1998, pp.297-325.

SPINOZA, Benedictus de. Ética Demonstra em Ordem Geométrica. Belo Horizonte, Autêntica, 2008.

SPIVAK, G. C. Pode o Subalterno Falar? Belo Horizonte, EDUFMG, 2010.

SEDGWICK, Eve Kosofsky. A epistemologia do armário. cadernos pagu (28), Campinas-SP, Núcleo de Estudos de Gênero-Pagu/Unicamp, janeiro-junho 2007, pp.19-54.

TCHEKHOv, Anton. A Gaivota. São Paulo, Cosac Naify, 2010. 